\title{
Glucose-derived AGEs promote migration and invasion of colorectal cancer by up-regulating Sp1 expression
}

\author{
Ruyuan Deng ${ }^{\mathrm{a}, 1}$, Huo Wu ${ }^{\mathrm{b}, 1}$, Hui Ran ${ }^{\mathrm{a}, 1}$, Xiang Kong ${ }^{\mathrm{a}}$, Lei Hu ${ }^{\mathrm{c}}$, Xiao Wang ${ }^{\mathrm{d}, *}$, Qing $\mathrm{Su}^{\mathrm{a}, * *}$ \\ a Department of Endocrinology, Xinhua Hospital, Shanghai Jiaotong University School of Medicine, 1665, Kong Jiang Road, Shanghai 200092, China \\ b Department of General Surgery, Shanghai Institute of Digestive Surgery, Ruijin Hospital, Shanghai Jiaotong University School of Medicine, Shanghai, China \\ c Shanghai Key Laboratory of Gastric Neoplasms, Shanghai Institute of Digestive Surgery, Ruijin Hospital, Shanghai Jiaotong University School of Medicine, Shanghai, China

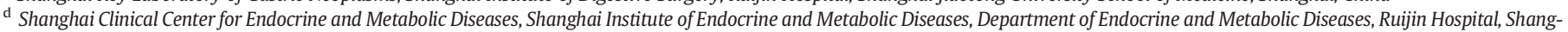 \\ hai Jiaotong University School of Medicine, Shanghai 200025, China
}

\section{A R T I C L E I N F O}

\section{Article history:}

Received 30 October 2016

Received in revised form 29 January 2017

Accepted 21 February 2017

Available online 22 February 2017

\section{Keywords:}

AGEs

RAGE

Sp1

Colorectal cancer

Migration

Invasion

\begin{abstract}
A B S T R A C T
It is well established that the risk of colorectal cancer (CRC) is significantly increased in diabetic patients. As one of main forms of the advanced glycation end products (AGEs) that accumulate in vivo, glucose-derived AGEs play an important role in the pathogenesis of diabetic complications and may contribute to CRC progression. However, to date, both the contribution of glucose-derived AGEs to the course of CRC and the underlying mechanism are unclear. In the present study, the concentration of glucose-derived AGEs in the serum and tumor tissue of patients with CRC increased. A clinical data analysis demonstrated that the expression of the receptor for AGEs (RAGE), Specificity Protein 1 (Sp1), and matrix metallopeptidase - 2 (MMP2) was significantly higher in cancerous tissues compared with non-tumor tissue in Chinese Han patients with CRC and that RAGE expression was closely associated with lymph node metastasis and TNM stage. Furthermore, in vivo and in vitro experiments showed that AGEs promoted invasion and migration of colorectal cancer, and the AGEs treatment increased the expression of RAGE, Sp1, and MMP2 in a dose-dependent manner. A RAGE blocking antibody and an Sp1-specific siRNA attenuated the AGE-induced effects. Moreover, the AGEs treatment increased the phosphorylation of ERK, and reducing the phosphorylation level of ERK by MEK1/2 inhibitor decreased the expression of Sp1. In conclusion, glucose-derived AGEs promote the invasion and metastasis of CRC partially through the RAGE/ERK/SP1/ MMP2 cascade. These findings may provide an explanation for the poor prognoses of colorectal cancer in diabetic patients.
\end{abstract}

(C) 2017 Elsevier B.V. All rights reserved.

\section{Introduction}

With the change of life style in modern society, diabetes mellitus, with a young-onset trend, has caused a heavy social and economic burden [1] and is closely associated with the increased incidence and mortality of colorectal cancer [2], which is the fourth leading cause of cancer-related death worldwide [3]. Accumulating evidence suggests that hyperglycemia and hyperinsulinemia may contribute to the occurrence and progression of some types of cancers [4-6]. Additionally, some anti-diabetic drugs, such as metformin and thiazolidinediones, reduce the incidence of cancer and cancer-related mortality [7]. It is well

\footnotetext{
* Correspondence to: X. Wang, Shanghai Institute of Endocrine and Metabolic Diseases, Department of Endocrine and Metabolic Diseases, Shanghai Clinical Center for Endocrine and Metabolic Diseases, Ruijin Hospital, Shanghai Jiaotong University School of Medicine,197 Ruijin Road II, Shanghai 200025, China.

** Corresponding author.

E-mail addresses: wangxiao1976@hotmail.com (X. Wang), suqingxinhua@163.com (Q. Su).

1 These authors contributed equally to this work.
}

known that the progression of cancer is a complicated chronic process that includes proliferation, invasion, metastasis, and angiogenesis [8]. Here, we aimed to explore new mechanisms by which metabolites abnormally accumulate in diabetic patients to contribute to the invasion and metastasis of cancer.

As one of the most common metabolites that abnormally accumulates in diabetic patients, advanced glycation end products (AGEs) are implicated in some chronic complications of diabetes [9-13]. The accumulation of AGEs in human serum is not only related to the intake of high-temperature baking food and smoking but is also associated with age-related diseases and chronic inflammation related-diseases, such as Alzheimer's disease, cardiovascular disease, stroke, nephropathy, and cancer $[14,15]$. Epidemiological evidence demonstrates that the serum concentration of glyceraldehydes-derived AGEs in patients with colorectal cancer is increased and is closely related to an increased risk of rectal cancer [16]. However, whether glucose-derived AGEs accumulate in the serum and tumor tissues of patients with colorectal cancer has not been reported to date. AGEs not only directly damage the organization, structure and function through the chemical modification of 
biological macromolecules, including proteins, lipids, nucleic acids and the cross-linking of collagen [17], but they can also bind to the receptor RAGE on the surface of target cells to affect their functions. Many receptors interact with AGEs, among which RAGE plays the most important role in mediating the AGE-induced pathological effects [18]. After binding with its ligands, including AGEs, S100A4, and HMGB1, RAGE regulates multiple signaling pathways, such as the NF-Кв, Ras-MAPK, and $\mathrm{Jak} /$ Stat cascades, which are involved in inflammation, cell proliferation and motility $[19,20]$. Our previous study showed that glucose-derived AGEs promote the proliferation of colorectal cancer cells by binding to RAGE and up-regulating the expression of carbohydrate-responsive element-binding protein (ChREBP) under glucose-free conditions [21]. As the receptor for glucose-derived AGEs, RAGE was recently reported to be highly expressed in colorectal cancer tissues and was closely associated with the invasion, metastasis, and angiogenesis of colorectal cancer $[22,23]$. Nevertheless, the serum concentration of glucose-AGEs in colorectal patients and whether glucose-AGEs are implicated in the invasion and metastasis of colorectal cancer remain to be investigated.

As the founding member of the Sp/KLF family, Sp1 is considered a general transcription factor that regulates numerous 'housekeeping genes', which are widely involved in metabolism, cell proliferation and death $[24,25]$. As reported, Sp1 contributes to the growth of colon cancer, which is inhibited by non-steroidal anti-inflammatory drugs (NSAIDs) [26]. Many studies have indicated that Sp1 is over-expressed in various types of tumors, such as breast, gastric, thyroid, lung, brain (glioma), pancreatic and colorectal cancers, which regulate the expressions of genes closely related to the biological behavior of cancers, including MMP2, MMP9, VEGF, and E-cadherin [25]. Therefore, the overexpression of $\mathrm{Sp} 1$ in tumor tissues is closely associated with the invasion, metastasis and prognosis of many cancers. Interestingly, with the knockdown of RAGE, Sp1 expression in colorectal cancer cells is also reduced, which suggests that the activation of the RAGE receptor might regulate the expression of Sp1 and thereby contribute to colorectal cancer progression.

The present study was designed to explore the role of glucose-derived AGEs in the invasion and metastasis of colorectal cancer and the underlying mechanism. Our results confirmed that RAGE expression in the tumor tissues of patients with colorectal cancer was increased, with an increased risk of cancer invasion and metastasis, and that the serum concentration and cancer tissue content of glucose-derived AGEs were increased as well. Furthermore, a series of long-term experiments in vivo and in vitro demonstrated that the AGEs-RAGE signal promoted cancer cell invasion and metastasis by increasing the protein expression of Sp1 and its target gene MMP2. These results may help shed light on the relationship between diabetes and progression of colorectal cancer and its underlying mechanism.

\section{Materials and methods}

\subsection{Reagents}

The primary antibodies for RAGE, MMP2 were purchased from Abcam and antibodies against Sp1, AKT, p-AKT, ERK, p-ERK, JNK, pJNK, p38, p-p38, Alexa Fluor ${ }^{\circledR} 488$ and Alexa Fluor ${ }^{\circledR} 594$ were purchased from Cell signaling technology. DAPI was purchased from Thermal Fisher Scientific (USA). U0126 (MEK1/2 inhibitor) was purchased from Selleckchem (Houston, USA).

\subsection{Clinic specimens and measure of serum glucose-derived AGEs}

160 sets of colorectal tumors and adjacent non-tumorous tissues (more than $5 \mathrm{~cm}$ away from primary tumor margin) were obtained from patients who underwent curative surgery in Ruijin Hospital affiliated to Shanghai Jiaotong University School of Medicine from 2012 to 2014. No preoperative radiotherapy or chemotherapy before surgery was performed. The pathological stage of tumor was evaluated strictly according to the criteria of UICC TNM classification. Histological type of tumor was determined independently by at least two pathologists in a double-blind way. The blood samples of patients were collected with tubes containing EDTA before surgery. All of the related studies were approved by Medical Ethics Committee of Shanghai Ruijin Hospital. Serum was obtained and preserved at $-80^{\circ} \mathrm{C}$ after blood was centrifuged at $3000 \mathrm{rpm}$, for $5 \mathrm{~min}$. The same volume of every patient's serum was mixed with non-denatured loading for western blot analysis. The content of glucose-derived AGEs in serum was detected with glucose-derived AGEs-specific antibody, and the content of serum total protein was detected by Coomassie brilliant blue staining.

\subsection{RNA extraction and real-time PCR}

The total RNA of tissue samples and cell lines was extracted with TRIzol reagent (Invitrogen, USA), according to manufacturer's instruction. The isolated RNA was reverse transcribed to cDNA using reverse transcription kit (Promega, Madision, WI, USA). qRT-PCR analysis was carried out using SYBR Green reagent (Takara Bio Inc., Japan) and an Applied Biosystems 7500. The forward and reverse primers designed for RAGE were 5'-ACTACCGAGTCCGAGTCTACC-3' and 5'-CCCACCTTATT AGGGACACTGG-3', respectively. The forward and reverse primers designed for GAPDH were 5'-GAGTCAACGGATTTGGTCGT-3' and 5'GACAAGCTTCCCGTTCTCAG-3', respectively.

\subsection{Western blotting analysis}

The protein lysates of cells or tissue specimens were prepared with RIPA buffer supplemented with protease inhibitors (Thermo Fisher Scientific, USA) and supernatant was obtained by centrifugation with $13,000 \mathrm{rpm}$ for $15 \mathrm{~min}$ at $4{ }^{\circ} \mathrm{C}$. The protein concentration was measured using BCA Protein assay kit (Pierce, Rockford, USA). An equal amount of protein $(20-50 \mu \mathrm{g})$ was separated by $10 \%$ SDS-PAGE gel and transferred to PVDF Membrane (Millipore, USA). After blocked with 10\% non-fat milk in TBST at room temperature for $2 \mathrm{~h}$, the membrane was incubated with primary antibodies overnight at $4{ }^{\circ} \mathrm{C}$, followed by incubation of secondary peroxidase-labeled antibody (Cell Signaling Technology, USA). Signals were detected by an enhanced chemiluminescence detection system.

\subsection{Preparation of AGES}

AGEs were prepared and purified as described by Takeuchi et al. [27]. In brief, $50 \mathrm{mg} / \mathrm{ml} \mathrm{BSA} \mathrm{(Sigma,} \mathrm{USA)} \mathrm{was} \mathrm{incubated} \mathrm{with} 0.5 \mathrm{mmol} / \mathrm{l} \mathrm{D}$ glucose (Sigma, USA) under sterile conditions for 8 weeks. The unincorporated sugar was removed by dialysis against $0.2 \mathrm{mmol} / \mathrm{lPB}$ ( $\mathrm{pH} 7.4$ ). $50 \mathrm{mg} / \mathrm{ml}$ nonglycated BSA was incubated under the same conditions except for the absence of D-glucose as a negative control. Preparations were tested for endotoxin using a Limulus Amebocyte Lysate (ACC, USA), and endotoxin was $<15 \mathrm{EU} / \mathrm{l}$.

\subsection{Cell culture}

All the colorectal cancer cell lines were purchased from ATCC (American Type Culture Collection) and kindly provided by Shanghai Digestive Surgery Institute. Leibovitz's L-15 medium containing 10\% FBS (Gibco, USA), and $2 \mathrm{mM}$ L-glutamine was used as culture medium for SW1116, SW480, and SW620. HCT116, Caco2, HT29, and LoVo were cultured in RPMI-1640 (Gibco, USA) supplemented with the same components. All the cell lines were cultured with or without $200 \mu \mathrm{g} / \mathrm{ml}$ glucose-derived AGEs under $37^{\circ} \mathrm{C}, 5 \% \mathrm{CO}_{2}$ and saturation humidity. In order to block RAGE function, $5 \mu \mathrm{g} / \mathrm{ml} \mathrm{RAGE-blocking} \mathrm{anti-}$ body (Santa Cruz, USA) or mouse serum lgG (sigma, USA) were added for $1 \mathrm{~h}$ before the treatment of AGEs. 


\subsection{Cell viability assay}

Cells were seeded at 2000 cells/well in 96-well plate for $24 \mathrm{~h}$ and were designed with six copies each group. After incubated in respective serum-poor medium (SPM) supplemented with 2.5\% FBS in the presence of various concentrations of AGEs or non-modified BSA for three days, cell viability was assessed with CCK8 (Beyotime, China). After incubation with CCK8 at $37{ }^{\circ} \mathrm{C}$ for $2 \mathrm{~h}$, OD was measured at $490 \mathrm{~nm}$ using spectrophotometer (Thermo Fisher Scientific, USA).

\subsection{Stable gene transfection}

Lentiviral expression vectors containing RAGE-specific shRNAs and green fluorescent protein (GFP) were constructed by GeneChem (Shanghai, China) and used to stably knock-down RAGE expression of LoVo cells. Briefly, LoVo cells were seeded on 6-well plates. 24 h later, cells were transfected with lentiviral expression vectors according to manufacturer's instructions (Shanghai GeneChem Co., Ltd.). For selection of stable clones, $5 \mu \mathrm{g} / \mathrm{ml}$ puromycin was administered for 7 weeks, followed by Western bolt analysis. The RAGE shRNA duplexes were as follows: S1 forward: 5'-CCGGGTGCCAGGCAATGAACAGGAA CTCGAGTTCCTGTTCATTGCCTGGCACTTTTTG-3', S1 reverse: 5'-AATTC AAAAAGTGCCAGGCAATGAACAGGAACTCGAGTTCCTGTTCATTGCCTGGCAC-3'; S2 forward: 5'-CCGGCACCTGACACATCTTGCAAAACTCGAG TTTTGCAAGATGTGTCAGGTGTTTTTG-3', S2 reverse: 5'-AATTCAAAA ACACCTGACACATCTTGCAAAACTCGAGTTTTGCAAGATGTGTCAGGTG-3'.

\subsection{Transwell migration and invasion assay}

In order to assess the ability of invasion and migration, $3 \times 10^{5}$ cells/ well were plated in transwell chamber ( $8 \mathrm{~mm}, 24$-well format; Corning, Lowell, MA, USA) and cultured in complete medium for $24 \mathrm{~h}$. Then the culture medium in upper chamber was changed to $200 \mu$ respective SPM in the presence of $200 \mu \mathrm{g} / \mathrm{ml}$ glucose-AGEs or non-modified BSA. The upper chambers were precoated with Matrigel (BD Bioscience, CA, USA) or not. Each condition was carried out in triplicate. After $72 \mathrm{~h}$ of incubation, the cells on upper side of inserts were removed with cotton swab. The cells under the inserts were fixed with methanol and stained with $1 \%$ crystal violet for cell counting by an inverted microscopy.

\subsection{Immunofluorescence}

Cells were plated on Millicell ${ }^{\circledR}$ EZ slides (Millipore, USA) at 2000 cells/well and cultured in complete medium for $24 \mathrm{~h}$. After incubated with or without $200 \mu \mathrm{g} / \mathrm{ml}$ AGEs for 3 days, cells were rinsed with $1 \times$ PBS for twice, fixed using 4\% paraformaldehyde for $10 \mathrm{~min}$ at room temperature (30 min for human CRC tissues) and then increased permeability of cells using $0.1 \%$ Triton X-100 for 5 min at room temperature. Incubation of cells with primary antibody overnight at $4{ }^{\circ} \mathrm{C}$ and subsequently with fluorescent secondary antibody for $1 \mathrm{~h}$ at room temperature were performed in turns. Finally, the slides were washed with $1 \times$ PBS for 3 times, subsequently mounted with Prolong Gold with DAPI (Invitrogen, USA) and imaged on fluorescence microscope (Leica, Germany). The level of RAGE protein expression in tumor and normal tissues was independently examined by two pathologists who were blinded from the patients' clinical data. According to the semi-quantitative immunoreactivity score (IRS), staining intensity was evaluated as negative (0), weak (1), moderate (2), or strange (3), and percentage of positive cells was classified as follows: $<10 \%(0)$, $10-25 \%(1), 25-50 \%(2), 50-75 \%(3)$, and $>75 \%(4)$. The total score was the multiplication of positive cell score and staining intensity score. And cases were grouped as negative $(\leq 2)$, weakly positive (2-5), and strongly positive $(\geq 5)$.

\subsection{Transient knockdown using siRNAs}

Control and Sp1 siRNA were purchased from Obio Technology Co., Ltd. (Shanghai, China). The siRNA transfection was carried out using lipofectamine 2000 according to manufacturer's protocol. The control SiRNA sequence was 5'-CCAACAGAUUAUCACAAAUDTDT-3'. The Sp1 siRNA sequence was 5'-AUUUGUGAUAAUCUGUUGGTDTD-3'.

\subsection{Gelatin zymography}

To assess the matrix metalloproteinase (MMP) activities, the medium used for cell invasion was collected and centrifuged at $1000 \mathrm{rpm}$, $4{ }^{\circ} \mathrm{C}$ for $5 \mathrm{~min}$. After determination of protein concentration, the samples were mixed with non-denatured gel sample loading buffer and subjected to electrophoresis on 10\% SDS-PAGE gels containing $1 \mathrm{mg} / \mathrm{ml}$ gelatin (Sigma, USA). The gels were washed with the Novex zymogram renaturing buffer (Invitrogen, USA) for $30 \mathrm{~min}$ at room temperature and then incubated in Novex zymogram developing buffer (Invitrogen, USA) at $37^{\circ} \mathrm{C}$ overnight. The Coomassie brilliant blue staining, and photographed were performed in turns.

\subsection{Nude mouse xenograft model}

Colorectal cancer xenografts were established in four-week-old male BALB/C nude mice (Institute of Zoology, Chinese Academy of Sciences of Shanghai). Briefly, $5 \times 10^{6}$ wild type or RAGE stably knockdown LoVo cells suspended in $100 \mu \mathrm{lBS}$ ( $\mathrm{pH}$ 7.4) were slowly injected into the portal vein in $5 \mathrm{~min}$ under sterile condition. Three days later, $30 \mathrm{mg} / \mathrm{kg}$ sterile AGEs or nonglycated BSA were administrated by intraperitoneal injection every other day. Mice were sacrificed two months later. CML was observed and photographed. All animal related operations were approved by the Institutional Animal Care and Use Committee (IACUC) at Shanghai Jiaotong University School of Medicine.

\subsection{Statistical analysis}

All of experiments were done in triplicate. Data were expressed as mean \pm SD and analyzed by SAS 8.0 statistical software. CochranMaantel-Terpstra test was used to examine the differential expression between tumor tissue and adjacent normal tissue. Correlations between the level of RAGE expression in CRC tissues and clinicopathological parameters were analyzed by chi-square or Fisher's exact tests. Student's $t$-test was used to analyze the statistical differences between two groups. $P<0.05$ and $P<0.01$ were respectively considered as statistically significant.

\section{Result}

3.1. Co-expression of RAGE, Sp1, and MMP2 in cancer tissue and glucosederived AGEs levels in the serum and tumor tissue of patients with colorectal cancer

To investigate the RAGE expression profile in colorectal cancer tissues, RT-PCR and immunofluorescence staining were performed on matched tumor and non-tumor tissues excised from 160 CRC patients without diabetes. RAGE mRNA expression was markedly higher in the tumor tissues than in the non-tumor tissues (Fig. 1A). Moreover, RAGE protein in the cell membrane demonstrated a higher expression in the invasive $\mathrm{CRC}$ tissues compared with the non-invasive CRC tissues (Fig. S1). Ninety-eight of the 160 (61.25\%) colorectal cancer tissues showed RAGE positive staining. Further, a correlation analysis between RAGE expression and the clinicopathological features revealed that the increased expression of RAGE in the CRC tissues was significantly related to lymph node metastasis $(P=0.025)$ and TNM stage $(P=0.01)$ but not to other factors (Table 1 ). 
A
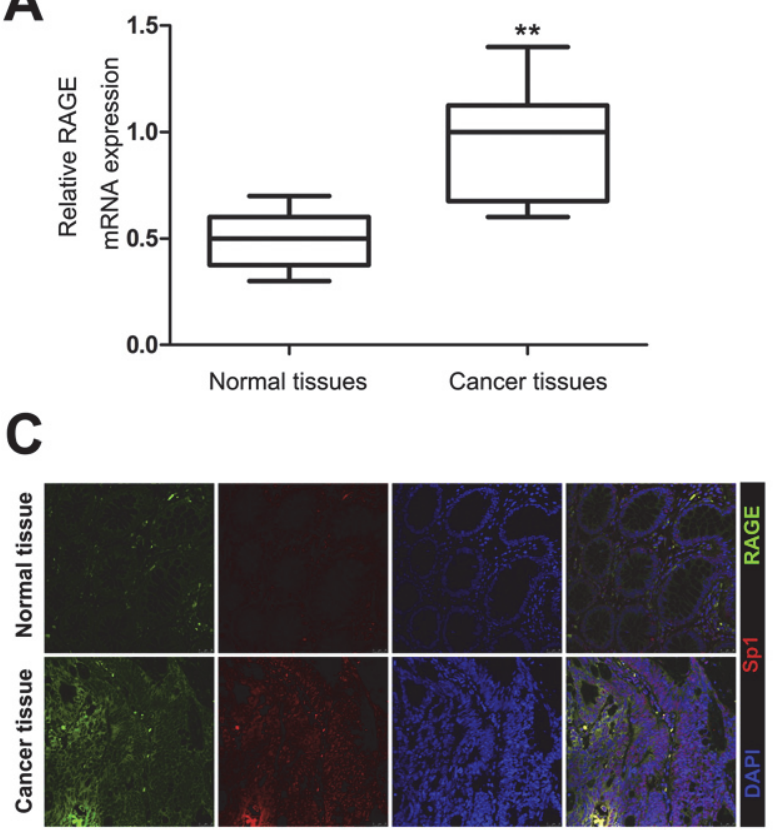

B

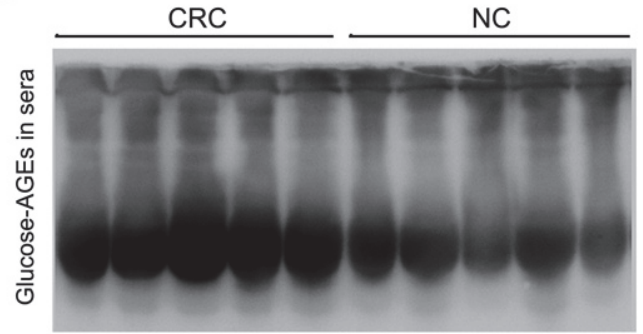

D

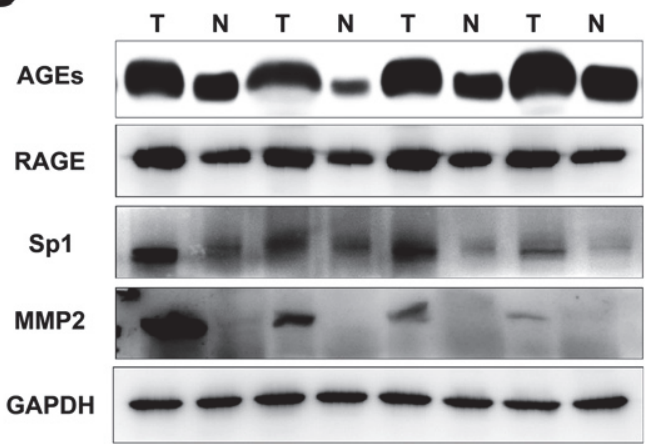

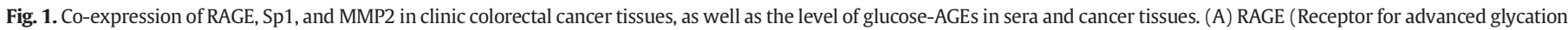

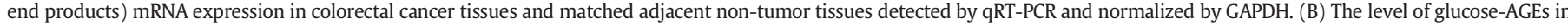

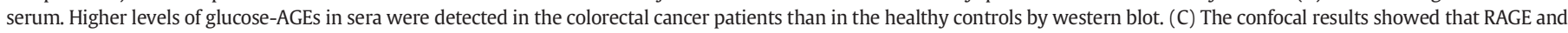

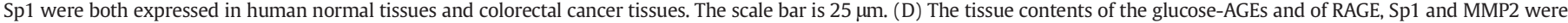
simultaneously found to be highly expressed in human colorectal cancer tissues by western blot.

It is well established that AGEs accumulate under the states of hyperglycemia, age, inflammation, and in some cancers and that they contribute to many pathological sequelae $[10,28]$. Although Coomassie brilliant blue staining showed that the content of serum total protein in CRC patients was lower than that in normal control (Fig. S2), with age standardization, our study still revealed that the serum level of

Table 1

Association between RAGE expression and clinicopathological factors of colorectal cancer patients

\begin{tabular}{|c|c|c|c|c|}
\hline \multirow[b]{2}{*}{ Variables } & \multirow[b]{2}{*}{ Number of cases } & \multicolumn{2}{|c|}{$\begin{array}{l}\text { RAGE immunofluorescence } \\
\text { staining }\end{array}$} & \multirow[b]{2}{*}{$P$} \\
\hline & & Positive(high/low) & Negative & \\
\hline \multicolumn{5}{|l|}{ Gender } \\
\hline Male & 107 & $64(38 / 26)$ & 43 & 0.596 \\
\hline Female & 53 & $34(18 / 16)$ & 19 & \\
\hline \multicolumn{5}{|l|}{ Age(years) } \\
\hline$\geq 60$ & 95 & $55(31 / 24)$ & 40 & 0.292 \\
\hline$<60$ & 65 & $43(25 / 18)$ & 22 & \\
\hline \multicolumn{5}{|l|}{ Differentiation } \\
\hline Well to moderate & 69 & $41(23 / 18)$ & 28 & 0.679 \\
\hline Poor & 91 & $57(33 / 24)$ & 34 & \\
\hline \multicolumn{5}{|l|}{ Tumor location } \\
\hline Colon & 81 & $51(29 / 22)$ & 30 & 0.540 \\
\hline Rectum & 79 & $47(27 / 20)$ & 32 & \\
\hline \multicolumn{5}{|l|}{ Tumor size } \\
\hline$\geq 5 \mathrm{~cm}$ & 75 & $43(27 / 16)$ & 32 & 0.339 \\
\hline$<5 \mathrm{~cm}$ & 85 & $55(29 / 26)$ & 30 & \\
\hline \multicolumn{5}{|l|}{ Lymph metastasis } \\
\hline Negative & 70 & $36(16 / 20)$ & 34 & 0.025 \\
\hline Positive & 90 & $62(40 / 22)$ & 28 & \\
\hline \multicolumn{5}{|l|}{ Distant metastasis } \\
\hline Negative & 151 & $91(50 / 41)$ & 60 & 0.295 \\
\hline Positive & 9 & $7(6 / 1)$ & 2 & \\
\hline \multicolumn{5}{|l|}{ TNM stage } \\
\hline $\mathrm{I}+\mathrm{II}$ & 70 & $35(14 / 21)$ & 35 & 0.010 \\
\hline III + IV & 90 & $63(42 / 21)$ & 27 & \\
\hline
\end{tabular}

AGEs in CRC patients without hyperglycemia was higher than that observed in healthy subjects (Fig. 1B), which suggests that AGEs might be involved in the progression of colorectal cancer.

In addition, our study revealed that RAGE and Sp1 were simultaneously expressed in human colorectal cancer tissues (Fig. 1C). Further, the expression levels of RAGE, Sp1, and MMP2, as well as the tissue content of AGEs, were higher in the tumor tissues than in the adjacent nontumor tissues (Fig. 1D). Considering the higher concentration of AGEs in the serum of patients with colorectal cancer, all of the results indicate that AGEs, RAGE, Sp1, and MMP2 are involved in the progression of colorectal cancer.

\subsection{AGEs promote colorectal liver metastasis in vivo}

To choose suitable CRC cell lines for the in in vivo and in vitro experiments, we detected the expression levels of RAGE among 8 CRC cell lines (LoVo, SW620, SW480, HCT116, RKO, SW1116, HT29, and Caco2). As shown in Fig. 2A and B, the expression abundances of RAGE were higher in the Lovo and SW620 cells, which were selected for further study.

Because RAGE mediates the AGE-induced physiological and pathological effects, we first transfected the LoVo cells with RAGE-specific shRNAs to stably knock-down RAGE expression (Fig. 2C) and explore its role in colorectal liver metastasis. According to a previous study [29], the xenograft model was established by a portal vein injection of wild type or RAGE-silenced LoVo cells and was then subjected to an AGEs intraperitoneal injection every other day for two months. The treatment with AGEs significantly promoted colorectal liver metastasis (Fig. 2D). Regardless of whether the animals received a BSA or the AGE intraperitoneal injection, the incidence of colorectal liver metastasis was reduced in the RAGE-silenced model compared with the wild type model (Fig. 2D, E). All of the results suggest that AGEs accelerate colorectal cancer progression by RAGE. 
A

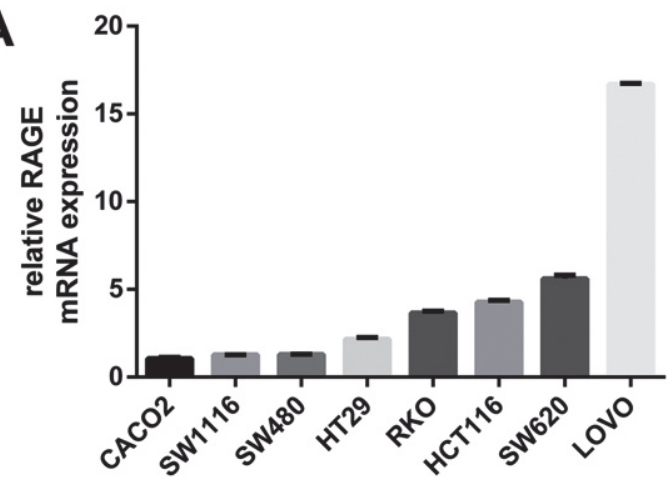

D

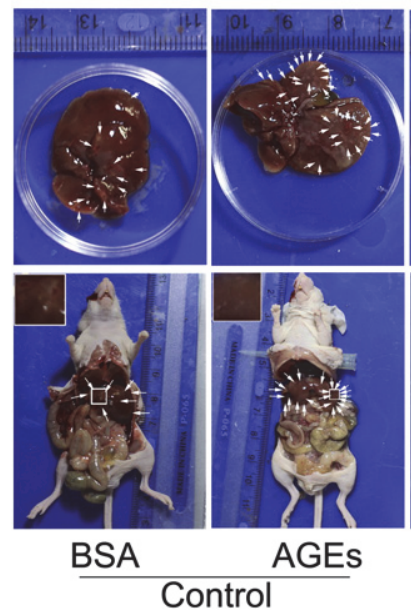

B

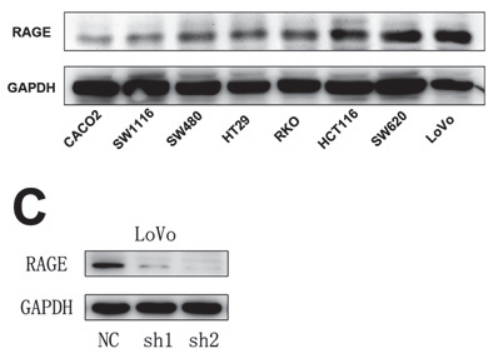

E

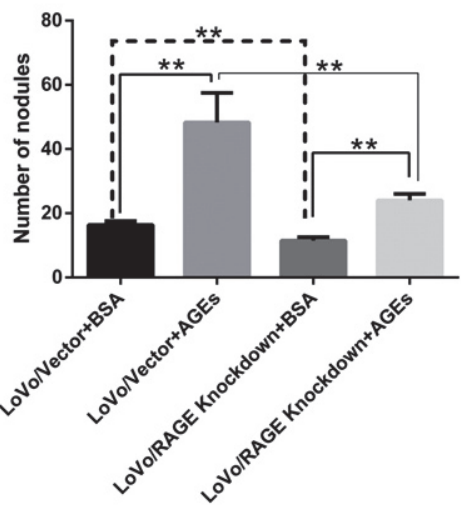

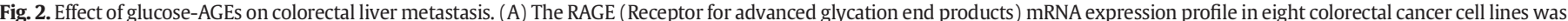

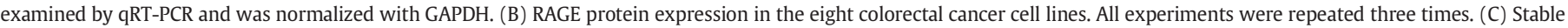

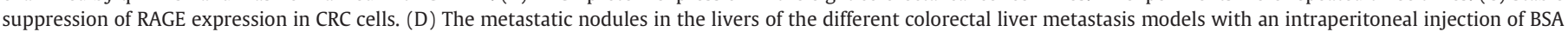

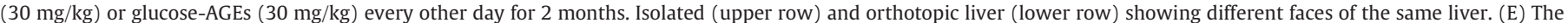
quantification of the metastatic nodules in the liver of the different colorectal liver metastasis model treated with BSA or glucose-AGEs via i.p. $\left({ }^{* *} P<0.01\right)$.

\section{A \\ migation \\ invasion}
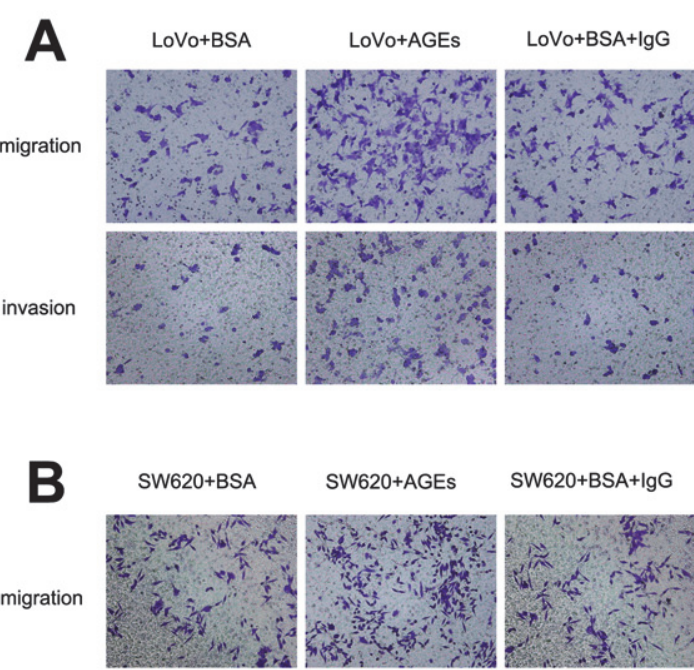

SW620+AGES+RAGE blocking antibody

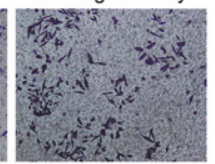

invasion
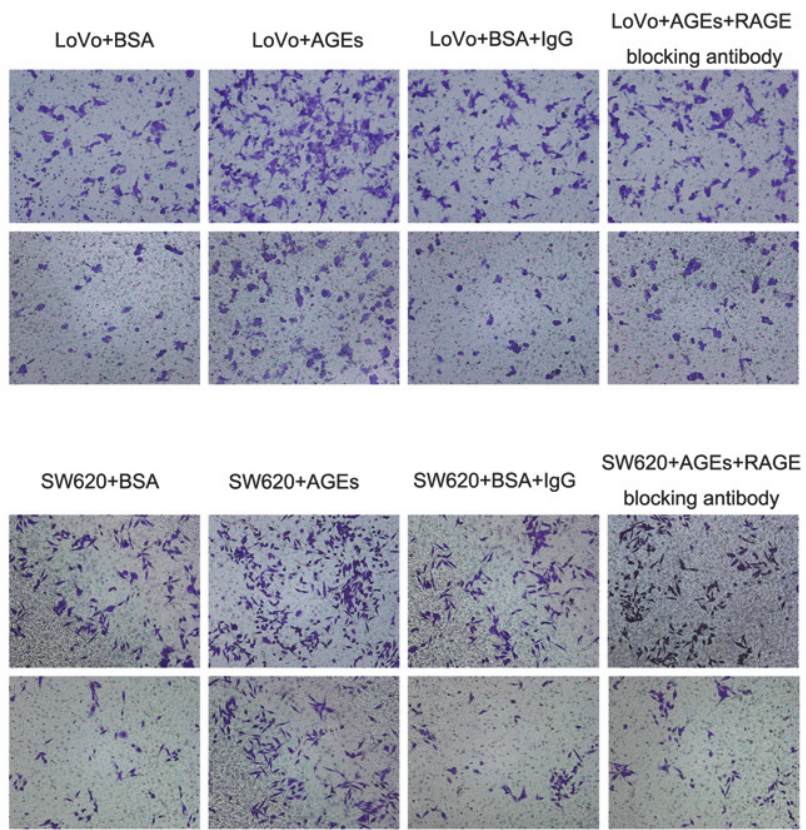

C

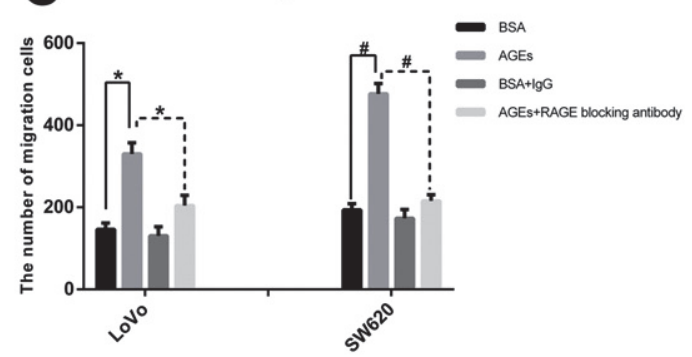

D

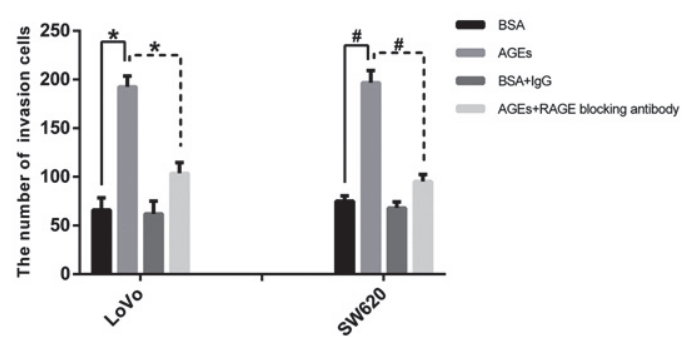

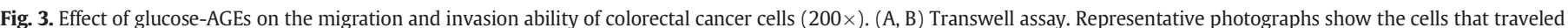

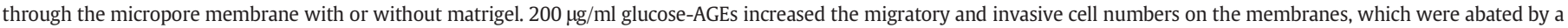

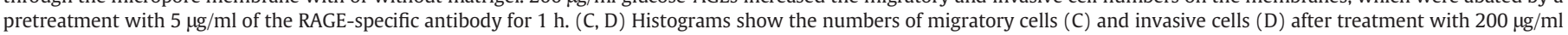

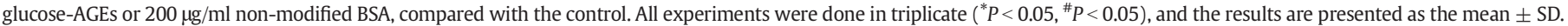




\subsection{AGEs promote the migration and invasion of colorectal cancer cells}

It is well known that migration and invasion are crucial parts of advanced cancer progression. Consistent with the results of the in vivo experiments, $200 \mu \mathrm{g} / \mathrm{ml}$ of the AGEs treatment for three days markedly increased the LoVo and SW620 cell migration and invasion rates (Fig. $3 A-D)$. Pretreatment with a $5 \mu \mathrm{g} / \mathrm{ml}$ RAGE-specific blocking antibody for $1 \mathrm{~h}$ counteracted the AGE-induced colorectal cancer cell migration and invasion (Fig. 3A-D) without any impairment on cell viability (Fig. S3A, B).
3.4. AGEs stimulate RAGE, Sp1, and MMP2 expressions in colorectal cancer cells

AGEs promote RAGE expression [30]. In the present study, a cell immunofluorescence assay demonstrated that RAGE expression on the cell membrane of LoVo and SW620 cells was up-regulated by AGEs (Fig. 4A, B). Furthermore, AGE treatment increased the protein expression of RAGE, Sp1, and MMP2 in a dose-dependent manner (Fig. 4C, D). Meanwhile, MMP2 activity was enhanced after AGE treatment (Fig. 4G). However, these AGE-induced effects were attenuated by a RAGE-

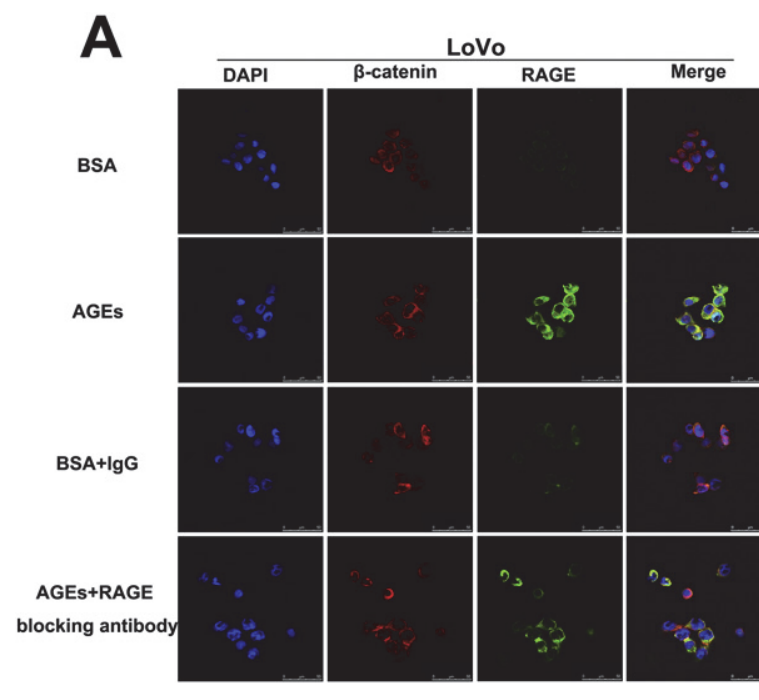

C

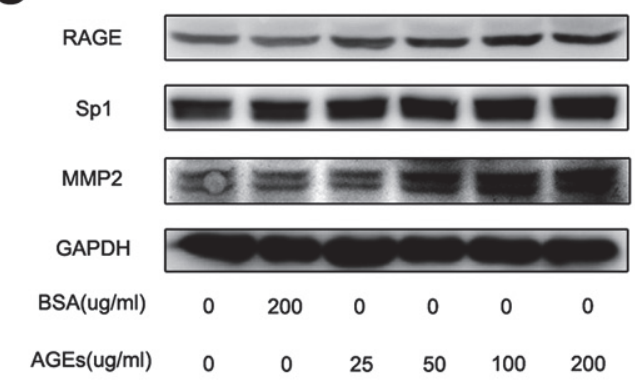

B

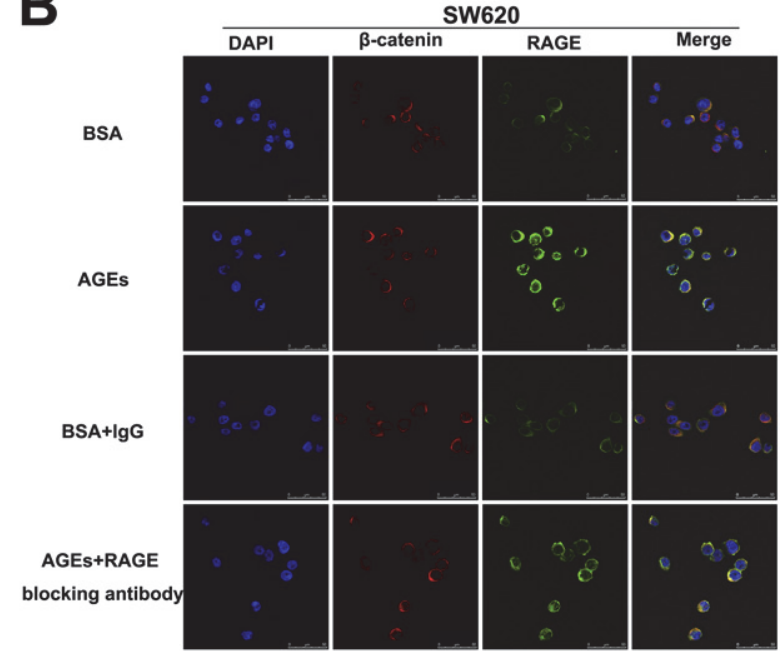

D

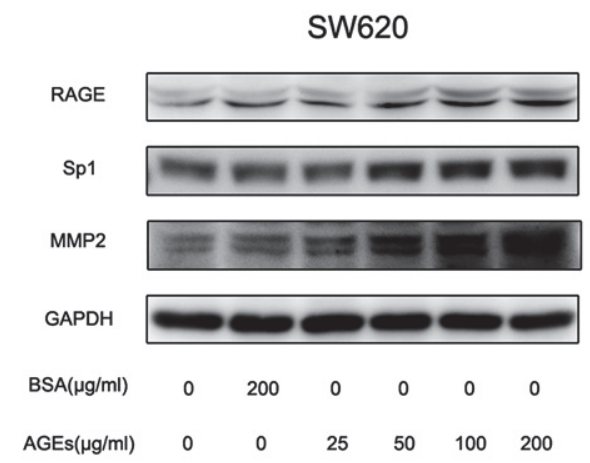

E

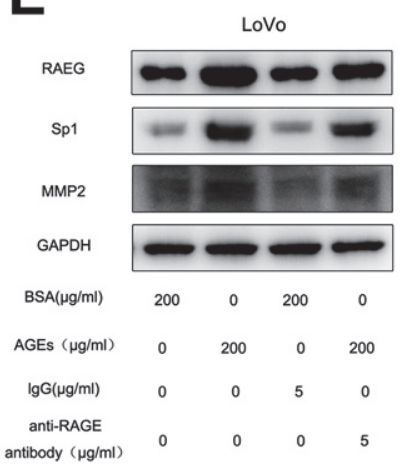

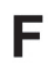

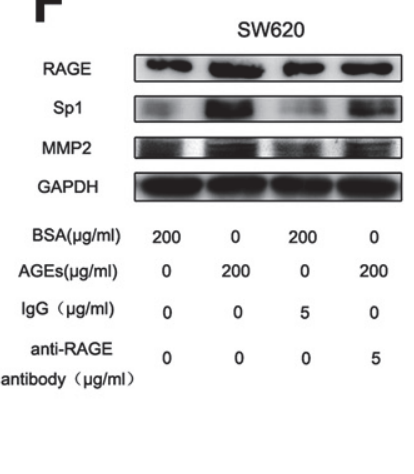

G

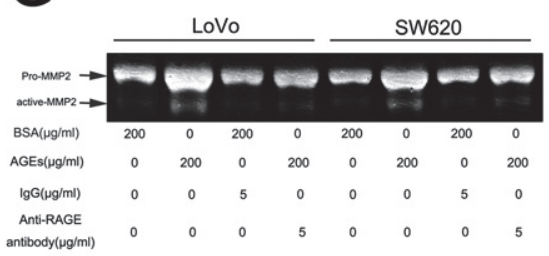

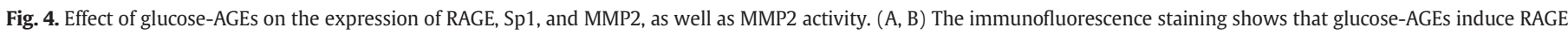

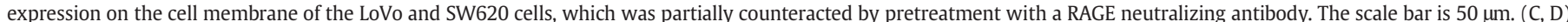

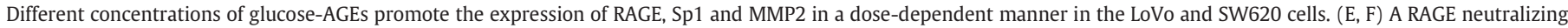

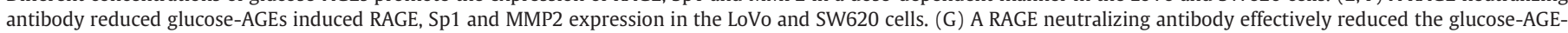
induced MMP2 enzyme activity enhancement in the LoVo and SW620 cells. 
specific blocking antibody pretreatment to some extent (Fig. 4E-G). These results indicate that AGEs up-regulate the expression of these three gene by binding to RAGE to influence the migration and invasion of colorectal cancer cells.

\subsection{Sp1 mediates AGE-induced migration and invasion of colorectal cancer} cells

As reported, Sp1 plays an important role in the progression of many cancers [25]. In our study, Sp1 was highly expressed in the cancer tissues of patients with colorectal cancer (Fig. 5A). To confirm the role of $\mathrm{Sp} 1$ in the AGE-induced migration and invasion of colorectal cancer, we knocked-down Sp1 expression in the LoVo and SW620 cells by siRNA (Fig. 5B). As expected, both the migration and invasion rates of the Sp1-silenced cells decreased, particularly under the AGEs treatment (Fig. 5C-F), which suggests that Sp1 mediates the AGE-/RAGE-induced migration and invasion of colorectal cancer cells.

\subsection{Sp1 mediates AGEs/RAGE/ERK/MMP2 cascade in colorectal cancer}

To further explore the underlying role of Sp1, the LoVo and SW620 cells were transfected with an Sp1 siRNA and were treated with $200 \mu \mathrm{g} / \mathrm{ml}$ AGEs for three days. AGEs increased the protein expression

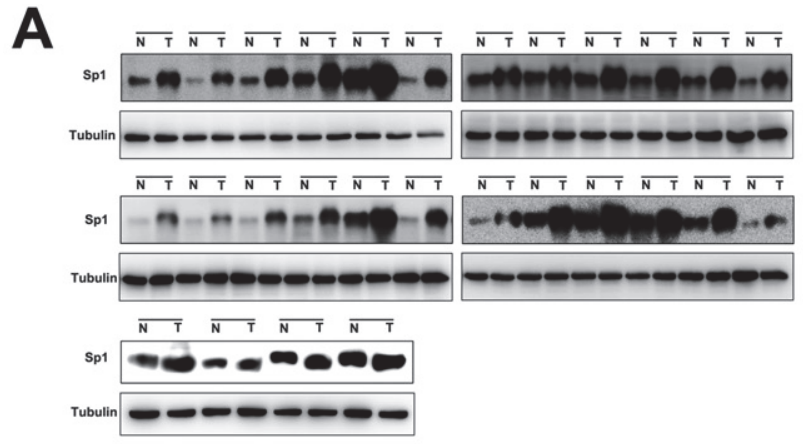

C
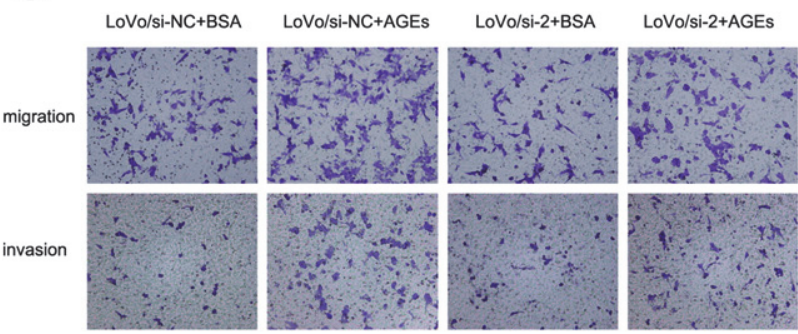

$\mathbf{E}$

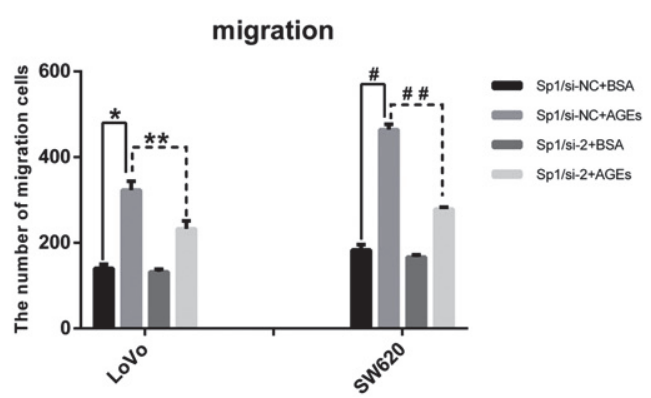

of RAGE, Sp1, and MMP2 (Fig. 6A-D). As one of the Sp1 target genes, MMP2 degrades the extracellular matrix to facilitate the migration and invasion of cancer cells [31]. Sp1 knockdown partially decreased MMP2 expression and its enzymatic activity in the presence of AGEs, without a significant effect on RAGE expression (Fig. 6A, C, E). Further, we found that AGEs activated ERK, but not AKT, in the Lovo and SW620 cells (Fig. 6F) and that preincubation with U0126, a MEK1/2 inhibitor, reduced both the phosphorylation level of ERK and Sp1 expression (Fig. 6G), which indicated that the activation of ERK mediated the AGE-induced Sp1 expression.

\section{Discussion}

Diabetes is closely associated with the initiation and development of site-specific tumors, including cancers of the endometrium, breast, and colorectum $[2,32]$. As a diabetes-related cancer, colorectal cancer is the fourth most common cause of cancer-related death, and almost half of all patients with advanced colorectal cancer already suffer from or will develop colorectal liver metastasis [33]. Our present findings showed that glucose-derived AGEs increased the invasion and hepatic metastasis of colorectal cancer partially through the RAGE/ERK/Sp1/MMP2 cascade, which may give us a deeper insight into the relationship between diabetes and colorectal cancer progression.

B

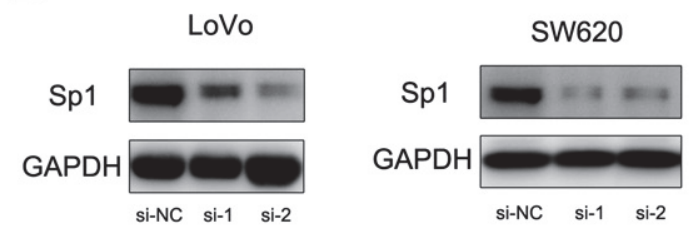

\section{D}

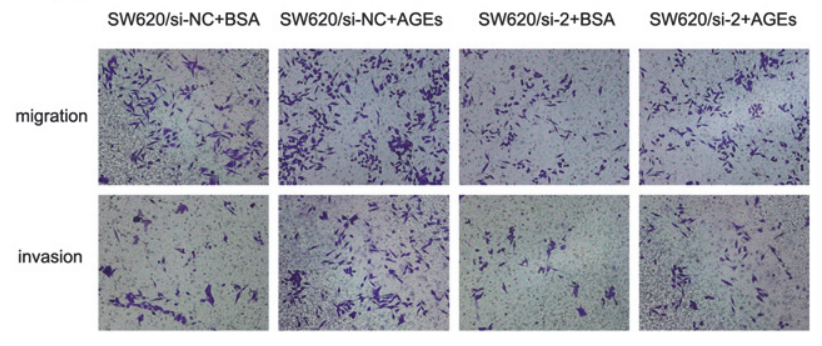

$\mathbf{F}$

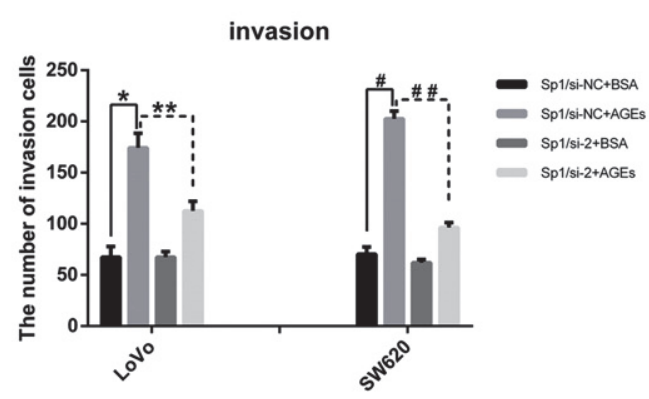

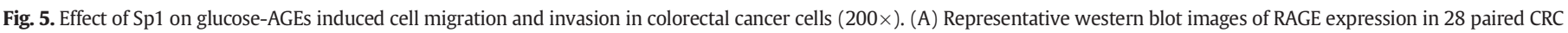

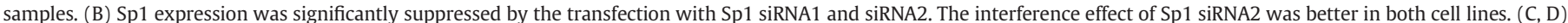

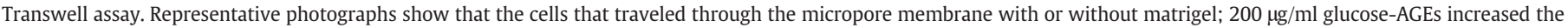

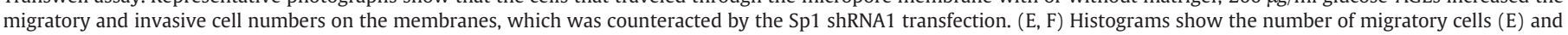
invasive cells (F). All of the experiments were done in triplicate $\left({ }^{*} P<0.05,{ }^{\#} P<0.05\right)$. 

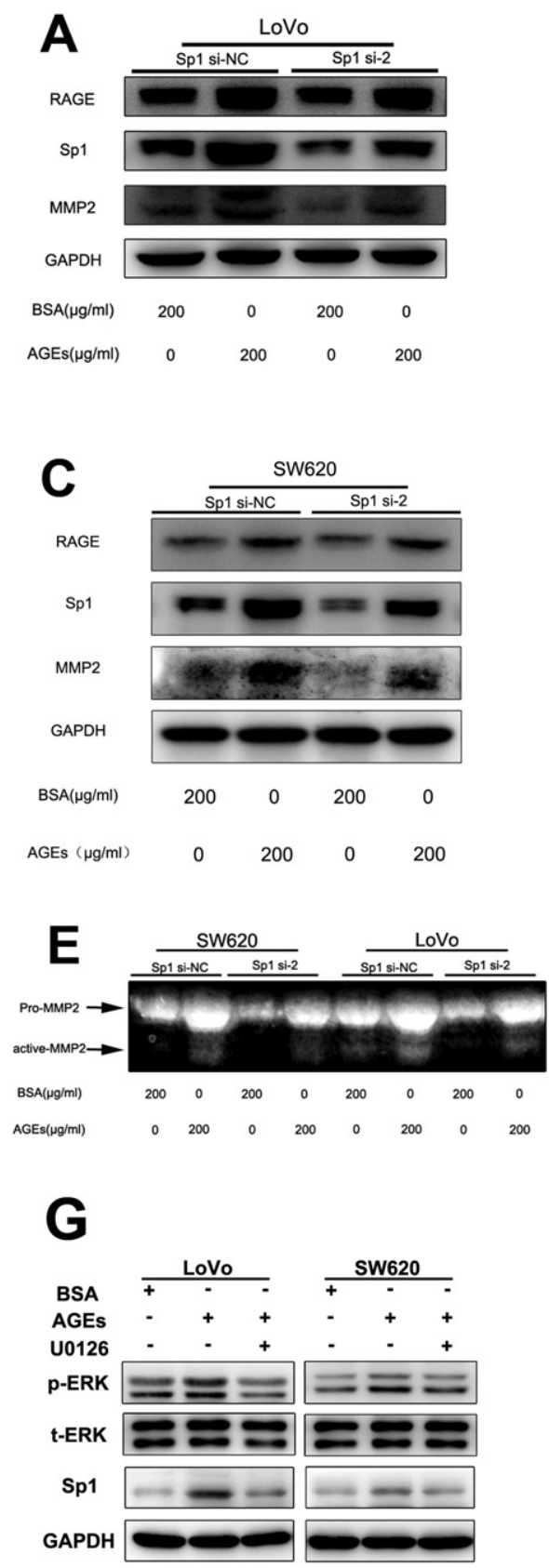
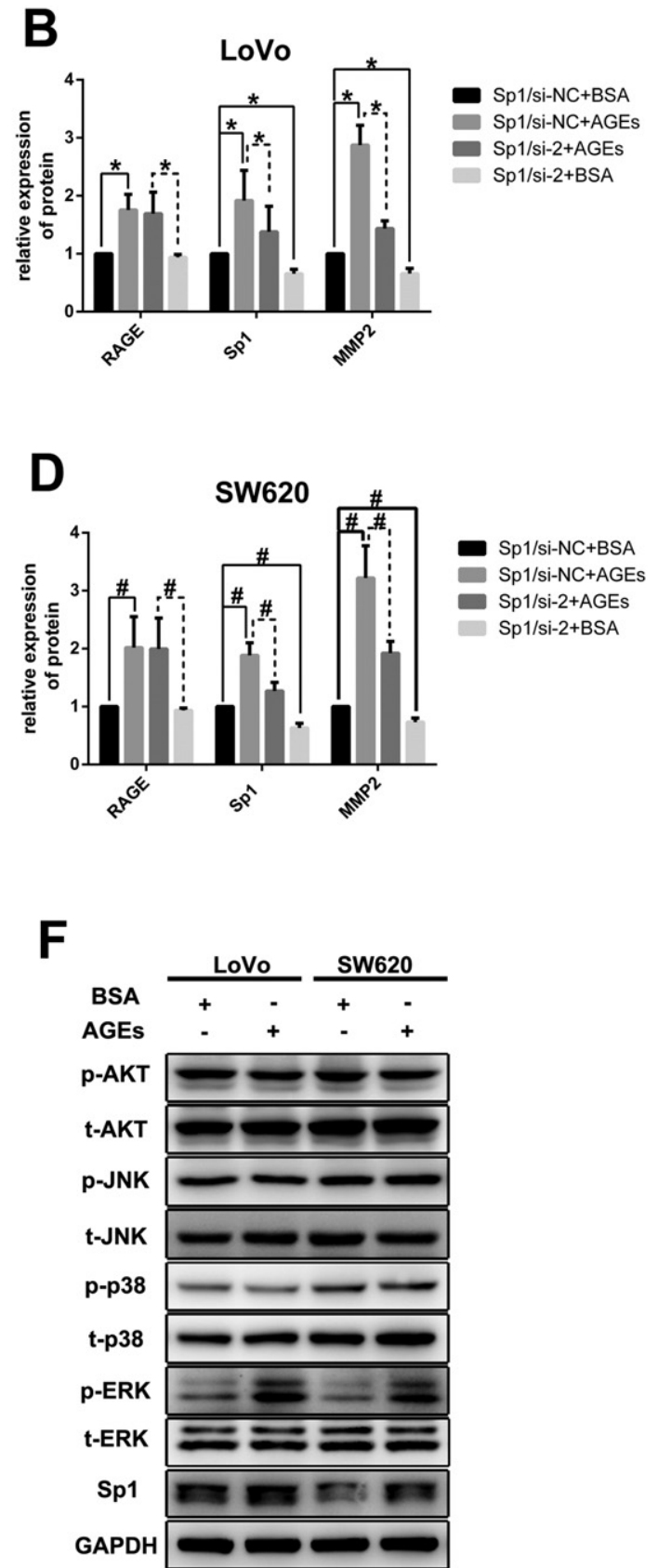

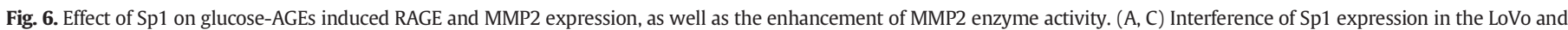

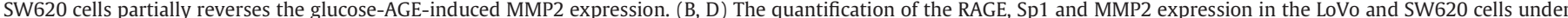

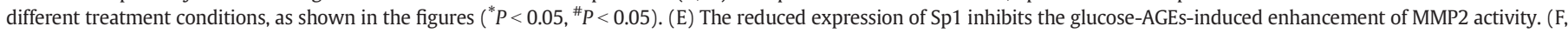

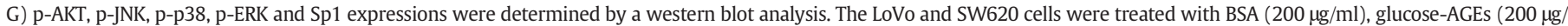
$\mathrm{ml})$, U0126 $(10 \mu \mathrm{M})$, or both for 3 days.

As the products of the non-enzymatic glycation of amino-containing molecules under hyperglycemia in vivo, AGEs always accumulate in diabetes. AGEs used to be divided into six subtypes, including glucosederived AGEs (AGE-1), glyceraldehyde-derived AGEs (AGE-2), glycolaldehyde-derived AGEs (AGE-3), methylglyoxal-derived AGEs (AGE-4), glyoxal-derived AGEs (AGE-5), and 3- deoxyglucosonederived AGEs (AGE-6) [27]. Glucose-AGEs have been widely studied. Because diabetes is an important determinant of survival for colorectal cancer cases, some early researchers hypothesized that increased levels of AGEs in colorectal cancer patients with diabetes possibly contribute to the poor prognosis of the cancer [34,35]. In fact, previous studies corroborated that AGEs contribute to the advancement of many cancers, such as hepatocellular carcinoma, melanoma, oral cancer, and breast cancer [15,36-38]. To date, the AGEs-RAGE axis is indicated to be associated with the clinical prognosis of colorectal cancer [39]. Recent epidemiological data show that glyceraldehyde-derived AGEs are enriched in the blood of patients with colorectal cancer, which is closely related to the increased risk of rectal cancer [16]. However, whether glucosederived AGEs are involved in the course of colorectal cancer remains to be elucidated. Here, our research first uncovered that the glucosederived AGE concentrations in both the circulation and in tumor tissues were increased in colorectal cancer and that an intraperitoneal injection of glucose-derived AGEs every other day for two months increased the incidence of colorectal liver metastasis in a nude mouse xenograft 
model. Similar to the in vivo result, an in vitro AGE treatment for three days promoted the invasion and metastasis of colorectal cancer cells. Therefore, it is important to investigate the diabetes-cancer link.

RAGE, different from other AGEs receptors, including CD36, scavenger receptors class A type II, class B type I and AGE receptors 1, 2, and 3, which are involved in the detoxification of AGEs, mediate AGE-induced signaling process [40]. It is known that chronic inflammation is not only a key feature of diabetes [41,42] but also paves the way to cancer metastasis [43,44] and that RAGE bridges inflammation and cancer [45]. Thus, RAGE could be a candidate cancer-related gene. Recently, RAGE was detected in many human cancers, including brain, lung, breast, colorectal, and ovarian cancer, and it enhances cancer formation [46,47]. The overexpression of RAGE in colorectal cancer is positively correlated with colorectal cancer invasion and metastasis [23]. The result of our study on the relationship between RAGE expression and colorectal cancer progression in Chinese Han patients was consistent with those of previous studies in other ethnic patients [23,48]. The glucose-derived AGE treatment dose-dependently increased RAGE expression in the colorectal cancer cells. A RAGE-neutralizing antibody pretreatment partially reversed the AGE-induced colorectal cancer cell migration and invasion. Moreover, RAGE knock-down reduced the incidence of the AGE-induced colorectal liver metastasis in a nude mouse model. All of the findings indicate that RAGE, rather than other receptors of AGEs, mediates the effects of AGEs in the invasion and metastasis of colorectal cancer.

As a basal transcription factor implicated in the so-called housekeeping genes that contain GC boxes in their promoters, Sp 1 is generally considered a negative tumor prognostic factor and is overexpressed in a number of human cancers, including colorectal, gastric, liver, pancreatic, breast, thyroid, brain (glioma), lung, and squamous cell carcinomas [25]. Many anti-inflammatory drugs, such as cyclooxygenase- 2 inhibitors, aspirin, and tolfenamic acid, inhibit colon cancer cell and tumor growth by down-regulating Sp1 [26,49,50]. Recently, Qin et al. reported that Sp1 was up-regulated in colorectal cancer tissues, which silenced the tumor suppressor miR-149 by increasing its methylation level and predicted a poor clinical outcome [51]. Here, we also observed the overexpression of Sp1 in human colorectal cancer. A high expression of RAGE protein in CRC tissues was accompanied by the overexpression of Sp1 and MMP2. In a previous study [22], Sp1 expression was reduced when RAGE was knocked-down in the colorectal cancer cell line SW480. All of these data hint that Sp1 might mediate RAGE-dependent signal transduction. In our study, AGEs treatment increased the protein expression of RAGE, Sp1, and MMP2 in colorectal cancer cells and enhanced cell migration and invasion. Sp1 knockdown reversed the above effects to some extent, without an effect on AGE-induced RAGE expression. These results suggest that the binding of AGEs to RAGE regulates Sp1 expression, and Sp1 mediates the AGE-/RAGE-dependent cascade. Some studies demonstrate that many factors, including HIF1a, ZEB2, and Sp1 itself, up-regulate Sp1 protein expression [52-54]. Specifically, the ZEB2-mediated up-regulation of Sp1, by enhancing its protein stability, induces the invasion of CRC cells. Here, we detected that the activation of ERK contributes to AGE-induced Sp1 expression. The MEK1/2/ERK signaling pathway was reported to be a complicated cascade that is involved in cancer metastasis [38]. However, the detailed mechanism underlying the increased Sp1 expression induced by AGEs remains unclear and needs to be further studied. As the effector molecule of Sp1, MMP2 degrades type IV collagen, the most abundant component of the basement membrane, to facilitate the metastasis of colorectal cancer [31]. As we know, Sp1 regulates the expression of many essential oncogenes, such as IGF, EGF, and PDGF [25], and possibly other Sp1 effectors exist.

Together, our results provide a novel insight into the poor prognosis of colorectal cancer complicated by diabetes. When diabetes coexists with colorectal cancer, glucose-AGEs/RAGE/ERK/Sp1/MMP2 signaling may contribute to the advancement of colorectal cancer progression, which may provide a rationale for targeting the glucose-AGE-RAGE axis as a novel strategy for clinical intervention.
Supplementary data to this article can be found online at http://dx. doi.org/10.1016/j.bbagen.2017.02.024.

\section{Conflicts of interest}

The authors disclose no potential conflicts of interest.

\section{Transparency document}

The Transparency document associated with this article can be found, in the online version.

\section{Acknowledgements}

This work was supported by grants from the National Science Foundation of China (30872727, 81370935).

\section{References}

[1] Y. Zhang, G. Ning, Diabetes: young-onset type 2 diabetes mellitus-a challenge for Asia, Nat. Rev. Endocrinol. 10 (2014) 703-704

[2] B.B. Barone, H.C. Yeh, C.F. Snyder, K.S. Peairs, K.B. Stein, R.L. Derr, A.C. Wolff, F.L. Brancati, Long-term all-cause mortality in cancer patients with preexisting diabetes mellitus: a systematic review and meta-analysis, JAMA 300 (2008) 2754-2764.

[3] H. Brenner, M. Kloor, C.P. Pox, Colorectal cancer, Lancet 383 (2014) 1490-1502.

[4] Y.I. Kim, Diet, lifestyle, and colorectal cancer: is hyperinsulinemia the missing link? Nutr. Rev. 56 (1998) 275-279.

[5] K. Esposito, P. Chiodini, A. Colao, A. Lenzi, D. Giugliano, Metabolic syndrome and risk of cancer: a systematic review and meta-analysis, Diabetes Care 35 (2012) 2402-2411.

[6] K. Aleksandrova, K. Nimptsch, T. Pischon, Influence of obesity and related metabolic alterations on colorectal cancer risk, Curr. Nutr. Rep. 2 (2013) 1-9.

[7] S.E. Inzucchi, Oral antihyperglycemic therapy for type 2 diabetes: scientific review, JAMA 287 (2002) 360-372.

[8] D. Hanahan, R.A. Weinberg, Hallmarks of cancer: the next generation, Cell 144 (2011) 646-674

[9] M. Brownlee, Glycosylation products as toxic mediators of diabetic complications, Annu. Rev. Med. 42 (1991) 159-166.

[10] M. Brownlee, Advanced protein glycosylation in diabetes and aging, Annu. Rev. Med. 46 (1995) 223-234.

[11] M. Brownlee, Biochemistry and molecular cell biology of diabetic complications, Nature 414 (2001) 813-820.

[12] N. Ahmed, Advanced glycation endproducts-role in pathology of diabetic complications, Diabetes Res. Clin. Pract. 67 (2005) 3-21.

[13] S. Yamagishi, S. Maeda, T. Matsui, S. Ueda, K. Fukami, S. Okuda, Role of advanced glycation end products (AGEs) and oxidative stress in vascular complications in diabetes, Biochim. Biophys. Acta 1820 (2012) 663-671.

[14] R. Singh, A. Barden, T. Mori, L. Beilin, Advanced glycation end-products: a review, Diabetologia 44 (2001) 129-146.

[15] R. Abe, T. Shimizu, H. Sugawara, H. Watanabe, H. Nakamura, H. Choei, N. Sasaki, S. Yamagishi, M. Takeuchi, H. Shimizu, Regulation of human melanoma growth and metastasis by AGE-AGE receptor interactions, J. Invest. Dermatol. 122 (2004) 461-467.

[16] S.Y. Kong, M. Takeuchi, H. Hyogo, G. McKeown-Eyssen, S. Yamagishi, K. Chayama, P.J. O'Brien, P. Ferrari, K. Overvad, A. Olsen, A. Tjonneland, M.C. Boutron-Ruault, N. Bastide, F. Carbonnel, T. Kuhn, R. Kaaks, H. Boeing, K. Aleksandrova, A. Trichopoulou, P. Lagiou, E. Vasilopoulou, G. Masala, V. Pala, M. Santucci De Magistris, R. Tumino, A. Naccarati, H.B. Bueno-de-Mesquita, P.H. Peeters, E. Weiderpass, J.R. Quiros, P. Jakszyn, M.J. Sanchez, M. Dorronsoro, D. Gavrila, E. Ardanaz, M. Rutegard, H. Nystrom, N.J. Wareham, K.T. Khaw, K.E. Bradbury, I. Romieu, H. Freisling, F. Stavropoulou, M.J. Gunter, A.J. Cross, E. Riboli, M. Jenab, W.R. Bruce, The association between glyceraldehyde-derived advanced glycation end-products and colorectal cancer risk, Cancer Epidemiol. Biomark. Prev. 24 (2015) 1855-1863.

[17] S.R. Thorpe, J.W. Baynes, Maillard reaction products in tissue proteins: new products and new perspectives, Amino Acids 25 (2003) 275-281.

[18] P.J. Thornalley, Cell activation by glycated proteins. AGE receptors, receptor recognition factors and functional classification of AGEs, Cell. Mol. Biol. (Noisy-le-Grand) 44 (1998) 1013-1023.

[19] C. Ott, K. Jacobs, E. Haucke, A. Navarrete Santos, T. Grune, A. Simm, Role of advanced glycation end products in cellular signaling, Redox Biol. 2 (2014) 411-429.

[20] J. Xie, J.D. Mendez, V. Mendez-Valenzuela, M.M. Aguilar-Hernandez, Cellular signalling of the receptor for advanced glycation end products (RAGE), Cell. Signal. 25 (2013) 2185-2197.

[21] H. Chen, L. Wu, Y. Li, J. Meng, N. Lin, D. Yang, Y. Zhu, X. Li, M. Li, Y. Xu, Y. Wu, X. Tong, Q. Su, Advanced glycation end products increase carbohydrate responsive element binding protein expression and promote cancer cell proliferation, Mol. Cell. Endocrinol. 395 (2014) 69-78.

[22] H. Liang, Y. Zhong, S. Zhou, L. Peng, Knockdown of RAGE expression inhibits colorectal cancer cell invasion and suppresses angiogenesis in vitro and in vivo, Cancer Lett. 313 (2011) 91-98 
[23] M. Dahlmann, A. Okhrimenko, P. Marcinkowski, M. Osterland, P. Herrmann, J. Smith C.W. Heizmann, P.M. Schlag, U. Stein, RAGE mediates S100A4-induced cell motility via MAPK/ERK and hypoxia signaling and is a prognostic biomarker for human colorectal cancer metastasis, Oncotarget 5 (2014) 3220-3233.

[24] A.R. Black, J.D. Black, J. Azizkhan-Clifford, Sp1 and kruppel-like factor family of transcription factors in cell growth regulation and cancer, J. Cell. Physiol. 188 (2001) 143-160.

[25] K. Beishline, J. Azizkhan-Clifford, Sp1 and the 'hallmarks of cancer', FEBS J. 282 (2015) 224-258.

[26] S. Pathi, X. Li, S. Safe, Tolfenamic acid inhibits colon cancer cell and tumor growth and induces degradation of specificity protein (Sp) transcription factors, Mol. Carcinog. 53 (Suppl. 1) (2014) E53-E61.

[27] M. Takeuchi, Y. Yanase, N. Matsuura, S. Yamagishi Si, Y. Kameda, R. Bucala, Z. Makita, Immunological detection of a novel advanced glycation end-product, Mol. Med. 7 (2001) 783-791.

[28] J.W. van Heijst, H.W. Niessen, K. Hoekman, C.G. Schalkwijk, Advanced glycation end products in human cancer tissues: detection of nepsilon-(carboxymethyl)lysine and argpyrimidine, Ann. N. Y. Acad. Sci. 1043 (2005) 725-733.

[29] G.M. de Jong, F. Aarts, T. Hendriks, O.C. Boerman, R.P. Bleichrodt, Animal models for liver metastases of colorectal cancer: research review of preclinical studies in rodents, J. Surg. Res. 154 (2009) 167-176.

[30] A. Bierhaus, P.M. Humpert, M. Morcos, T. Wendt, T. Chavakis, B. Arnold, D.M. Stern, P.P. Nawroth, Understanding RAGE, the receptor for advanced glycation end products, J. Mol. Med. 83 (2005) 876-886.

[31] O.R. Mook, W.M. Frederiks, C.J. Van Noorden, The role of gelatinases in colorectal cancer progression and metastasis, Biochim. Biophys. Acta 1705 (2004) 69-89.

[32] B. Carstensen, M.E. Jorgensen, S. Friis, The epidemiology of diabetes and cancer, Curr. Diab. Rep. 14 (2014) 535.

[33] G. Steele Jr., T.S. Ravikumar, Resection of hepatic metastases from colorectal cancer. Biologic perspective, Ann. Surg. 210 (1989) 127-138.

[34] S. Yamagishi, K. Nakamura, H. Inoue, S. Kikuchi, M. Takeuchi, Possible participation of advanced glycation end products in the pathogenesis of colorectal cancer in diabetic patients, Med. Hypotheses 64 (2005) 1208-1210.

[35] X. Hu, Y. Cheng, Possible participation of receptor for advanced glycation end products (RAGE) in the origin of cancer stem cells in diabetic patients with colon cancer, Med. Hypotheses 80 (2013) 620-623.

[36] J. Takino, S. Yamagishi, M. Takeuchi, Glycer-AGEs-RAGE signaling enhances the angiogenic potential of hepatocellular carcinoma by upregulating VEGF expression, World J. Gastroenterol. 18 (2012) 1781-1788.

[37] S.Y. Ko, H.A. Ko, T.M. Shieh, W.C. Chang, H.I. Chen, S.S. Chang, I.H. Lin, Cell migration is regulated by AGE-RAGE interaction in human oral cancer cells in vitro, PLoS One 9 (2014), e110542.

[38] H. Sharaf, S. Matou-Nasri, O Wang Z Rabhan, H. Al-Eidi, A. Al Abdulrahman, N. Ahmed, Advanced glycation endproducts increase proliferation, migration and invasion of the breast cancer cell line MDA-MB-231, Biochim. Biophys. Acta 1852 (2015) 429-441.
[39] S. Sakellariou, P. Fragkou, G. Levidou, A.N. Gargalionis, C. Piperi, G. Dalagiorgou, C. Adamopoulos, A. Saetta, G. Agrogiannis, I. Theohari, S. Sougioultzis, P. Tsioli, I. Karavokyros, N. Tsavaris, I.D. Kostakis, A. Zizi-Serbetzoglou, G.P. Vandoros, E. Patsouris, P. Korkolopoulou, Clinical significance of AGE-RAGE axis in colorectal cancer: associations with glyoxalase-I, adiponectin receptor expression and prognosis, BMC Cancer 16 (2016) 174.

[40] G. Marsche, B. Weigle, W. Sattler, E. Malle, Soluble RAGE blocks scavenger receptor CD36-mediated uptake of hypochlorite-modified low-density lipoprotein, FASEB J. 21 (2007) 3075-3082.

[41] G.S. Hotamisligil, Inflammation and metabolic disorders, Nature 444 (2006) 860-867.

[42] K.E. Wellen, G.S. Hotamisligil, Inflammation, stress, and diabetes, J. Clin. Invest. 115 (2005) 1111-1119.

[43] S.B. Coffelt, K.E. de Visser, Cancer: inflammation lights the way to metastasis, Nature 507 (2014) 48-49.

[44] L.M. Coussens, Z. Werb, Inflammation and cancer, Nature 420 (2002) 860-867.

[45] A. Riehl, J. Nemeth, P. Angel, J. Hess, The receptor RAGE: bridging inflammation and cancer, Cell Commun. Signal 7 (2009) 12

[46] B.C. Onyeagucha, M.E. Mercado-Pimentel, J. Hutchison, E.K. Flemington, M.A. Nelson, S100P/RAGE signaling regulates microRNA-155 expression via AP-1 activation in colon cancer, Exp. Cell Res. 319 (2013) 2081-2090.

[47] P. Malik, N. Chaudhry, R. Mittal, T.K. Mukherjee, Role of receptor for advanced glycation end products in the complication and progression of various types of cancers, Biochim. Biophys. Acta 1850 (2015) 1898-1904.

[48] O. Turovskaya, D. Foell, P. Sinha, T. Vogl, R. Newlin, J. Nayak, M. Nguyen, A. Olsson, P.P. Nawroth, A. Bierhaus, N. Varki, M. Kronenberg, H.H. Freeze, G. Srikrishna, RAGE, carboxylated glycans and S100A8/A9 play essential roles in colitis-associated carcinogenesis, Carcinogenesis 29 (2008) 2035-2043.

[49] M. Abdelrahim, S. Safe, Cyclooxygenase-2 inhibitors decrease vascular endothelia growth factor expression in colon cancer cells by enhanced degradation of Sp1 and Sp4 proteins, Mol. Pharmacol. 68 (2005) 317-329.

[50] S. Pathi, I. Jutooru, G. Chadalapaka, V. Nair, S.O. Lee, S. Safe, Aspirin inhibits colon cancer cell and tumor growth and downregulates specificity protein (Sp) transcription factors, PLoS One 7 (2012), e48208.

[51] F. Wang, Y.L. Ma, P. Zhang, T.Y. Shen, C.Z. Shi, Y.Z. Yang, M.P. Moyer, H.Z. Zhang, H.Q. Chen, Y. Liang, H.L. Qin, SP1 mediates the link between methylation of the tumour suppressor miR-149 and outcome in colorectal cancer, J. Pathol. 229 (2013) 12-24.

[52] J.K. Jeong, S.Y. Park, Transcriptional regulation of specific protein 1 (SP1) by hypoxia-inducible factor 1 alpha (HIF-1alpha) leads to PRNP expression and neuroprotection from toxic prion peptide, Biochem. Biophys. Res. Commun. 429 (2012) 93-98.

[53] E.H. Nam, Y. Lee, X.F. Zhao, Y.K. Park, J.W. Lee, S. Kim, ZEB2-Sp1 cooperation induces invasion by upregulating cadherin-11 and integrin alpha5 expression, Carcinogenesis 35 (2014) 302-314.

[54] M. Nicolas, V. Noe, K.B. Jensen, C.J. Ciudad, Cloning and characterization of the 5' flanking region of the human transcription factor Sp1 gene, J. Biol. Chem. 276 (2001) 22126-22132. 